\title{
Role of ruminal and oropharyngeal signals in the control of food intake by dry cows
}

\author{
C Perpère, R Baumont, O Daveau \\ INRA, Station de recherches sur la nutrition des herbivores, Theix, 63122 St-Genès-Champanelle, France
}

In ruminants, oropharyngeal and ruminal (mechanical and chemical) stimuli are the starting points of intake regulation process. The separation of the three types of stimuli can help to understand how they are integrated by animal's brain (Greenhalgh and Reid, 1971, Brit J Nutr, 26, 107-116).

Four rumen fistulated dry cows were fed hay ad libitum with one distribution per day. According to a latin square design, the cows received every four days one of the following treatments : control (only hay), barley pellets (2.7 kg DM) ingested (I) $30 \mathrm{~min}$ before distribution of hay, the pellets introduced in the rumen $(R)$ after mixing with $4 \mathrm{I}$ of artificial saliva, barley introduced in the rumen without increasing fill (RWIF). The latter was done by removing 6.21 of rumen content before introducing the pellets. A first experiment was performed with timothy grass hay and a second one with lucerne hay. Lucerne hay is known to be more palatable and less bulky than timothy grass hay. For each experiment, the latin square was repeated 3 times. Kinetics of hay intake and chewing behaviour were recorded during all the experiments (Baumont et al, 1990, J Agric Sci, 115, 277-284).

For Timothy grass hay, treatment I reduced significantly hay intake during the first hour following distribution and during the whole day. Hay intake was also decreased on the following day. When only ruminal stimuli were present $(R)$, decreases in hay intake were lower and still lower when only chemical stimuli were present (RWIF). For alfalfa hay, no significant differences were observed between treatments, although daily hay intake was slightly reduced with treatment $I$ and $R$.

Those results illustrate the importance of oropharyngeal stimuli in the short-term satiation process and thus in the hayconcentrate substitution phenomenon. Particularly when two different foods are successively ingested, differences between their organoleptic characteristics play probably an important role in the control of intake.

\begin{tabular}{|c|c|c|c|c|c|c|c|c|}
\hline \multirow[t]{2}{*}{ - $\quad-$} & \multirow{2}{*}{$\overline{\text { Control }}$} & \multicolumn{2}{|c|}{ Timothy } & \multirow{2}{*}{ RWIF } & --- & $\cdots$ & $\begin{array}{c}- \\
\text { Alfalfa }\end{array}$ & \multirow[b]{2}{*}{ RWIF } \\
\hline & & I & $R$ & & Control & । & $\mathrm{R}$ & \\
\hline \multicolumn{9}{|l|}{ Treatment day: } \\
\hline Daily hay intake (k & $7.89^{a}$ & $7.00^{\mathrm{b}}$ & $7.48^{\mathrm{ab}}$ & 85 & 10.86 & 10.40 & 9.92 & 10.61 \\
\hline First hour (kg DM) & $1.55^{\mathrm{a}}$ & $1.26^{b}$ & $1.56^{a}$ & $.43 \mathrm{ab}$ & 1.39 & 1.52 & 1.84 & 1.79 \\
\hline \multicolumn{9}{|l|}{ Following day: } \\
\hline Daily hay intake $(\mathrm{kg} \mathrm{D}$ & 8.35 & $7.14 \mathrm{~b}$ & $7.76^{a b}$ & $7.76^{\mathrm{ab}}$ & 10.87 & 10.06 & 10.46 & 10.37 \\
\hline First hour (kg DM) & $1.66^{\mathrm{a}}$ & $1.23^{b}$ & $1.31^{\mathrm{b}}$ & $1.41^{\mathrm{ab}}$ & 1.77 & 1.53 & 1.64 & 1.37 \\
\hline
\end{tabular}

For Timothy grass, means with different superscripts differ significantly $(P<0.05)$. 